\title{
Plasma transferred arc forming technology for remanufacture
}

\author{
Yao-Hui Lü • Yu-Xin Liu • Fu-Jia Xu • \\ Bin-Shi Xu
}

Received: 10 October 2012/Accepted: 2 January 2013/Published online: 28 April 2013

(C) Shanghai University and Springer-Verlag Berlin Heidelberg 2013

\begin{abstract}
The plasma transferred arc (PTA) forming remanufacturing technology was introduced in this paper. This technology includes plasma surfacing, deposition and rapid forming technology. With self-developed plasma forming system, the thrust of engine cylinder body was remanufactured by PTA powder surfacing. In the concrete, the Ni15 alloy was deposited on the thrust face of the body in order to recover its dimension. In addition, the remanufacturing forming with Fe-based, Inconel 625 alloy was studied. The microstructure and hardness of the as-deposited materials were investigated.
\end{abstract}

Keywords Plasma transferred arc (PTA) .

Forming remanufacturing $\cdot$ Microstructure $\cdot$ Hardness

\section{Introduction}

As a classical welding technology, the plasma arc welding extended a new field in remanufacture technology. It can not only remanufacture damaged parts, but also form a new part with rapid forming process [1-4]. As a kind of thermal resource, the plasma arc had high energy density and high temperature. Thus in the condition of same heat input for melting metal material, the plasma arc had less heataffected zone than other electric arc, and the metal material had less distortion. The National Key Laboratory for Remanufacturing had developed the new type plasma transferred arc (PTA) forming system. It can fulfill multi-

Y.-H. Lü $(\bowtie)$ · Y.-X. Liu · F.-J. Xu · B.-S. Xu

Science and Technology on Remanufacturing Laboratory,

The Academy of Armored Forces Engineering,

Beijing 100072, People's Republic of China

e-mail: 1yh163361@163.com metal parts remanufacture, especially for some heat sensitive metal parts, such as the leaf of aero-engine and combustion turbine. With this new type PTA forming system, the cast iron, heat-resistant steel and titanium alloy parts were remanufactured. Our recent research achievements and our prospect on PTA forming remanufacturing technology is introduced in this paper.

\section{Research field of PTA forming remanufacturing technology}

\subsection{Development of PTA forming remanufacturing system}

Figure 1 showed the PTA forming remanufacturing system. Using modularized design concept, the system was divided into PTA power supply unit, cooling unit, powder feed unit, operating mechanism and process computer unit, etc. This system can remanufacture a damaged part with programmable PTA welding route. All the units were controlled by the industrial control computer, such as turning on the cooling system, igniting the plasma arc, feeding the metal powder and starting the operating mechanism, hence it can reduce the labor intensity of operator. Especially the PTA power was designed with high frequency pulse wide modulation (PWM) inversion technology. The PTA power supply includes of pilot arc power supply and main arc power supply, and the current mode control technology was used in the converters of power supply. The PTA forming remanufacturing could remanufacture the titanium alloy, nickelbase alloy and other precious metal parts, such as the blade of aviation engine, the gas-turbine wheel and the steam turbine blade. Those parts were made by noble metal alloy with heat-strengthened process. Thus the heat input could be 


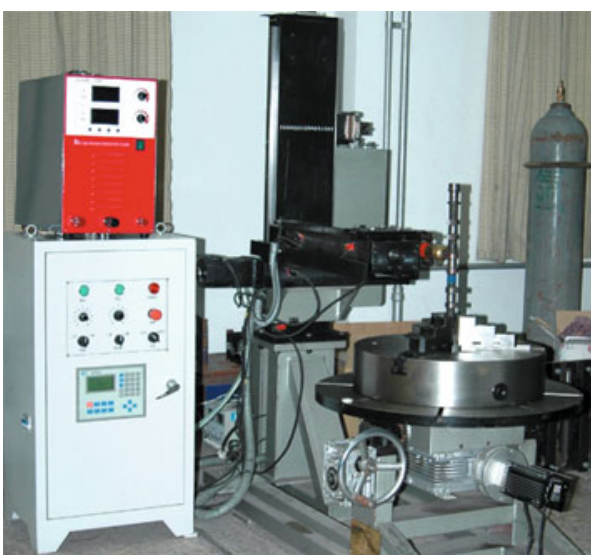

Fig. 1 Self-developed PTA forming remanufacturing system

controlled strictly. The PTA forming technology could meet the requirement of the remanufacture quality.

\subsection{Remanufacture of damaged metal parts}

The major function of PTA forming remanufacturing system was to remanufacture the damaged parts, especially those products those yield a high added value. Taking the engine cylinder as an example, the thrust face of the body was often wore out. Thus the crankshaft assembled on the cylinder could shift on the axial direction, and the engine could not work stably. In order to recover the dimension of the thrust face, the Ni15 alloy was built-up by PTA powder remanufacturing technology $[5,6]$. The test results showed that microstructure of Ni-based deposition layer was austenitic structure, and no chill was found. The hardness accorded with that of base metal, which met the repair requirement of cylinder body. Figure 2 illustrated the line scan of bond zone (EDAX), and it showed that the chromium and nickel of the deposition layer did not diffuse in the base metal. Figure 3 showed the hardness of the deposition layer.

\subsection{Rapid forming of Inconel $625 \mathrm{Ni}$-based superalloy}

Ni-based superalloy Inconel 625 is widely applied in aeronautical, aerospace, chemical, petrochemical and marine

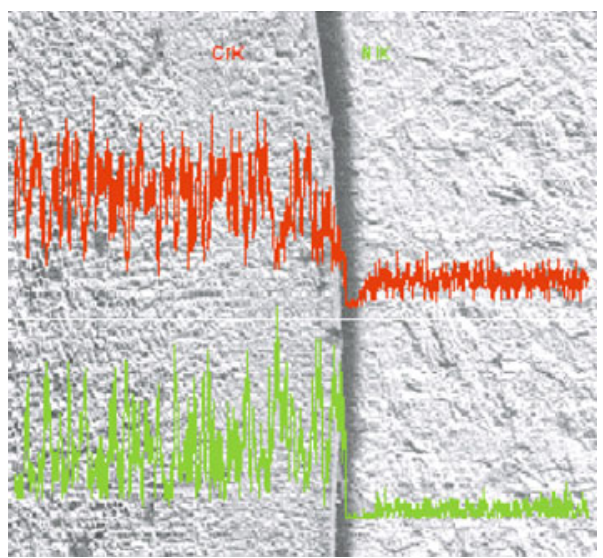

Fig. 2 Line scan of bond zone (EDAX) [5]

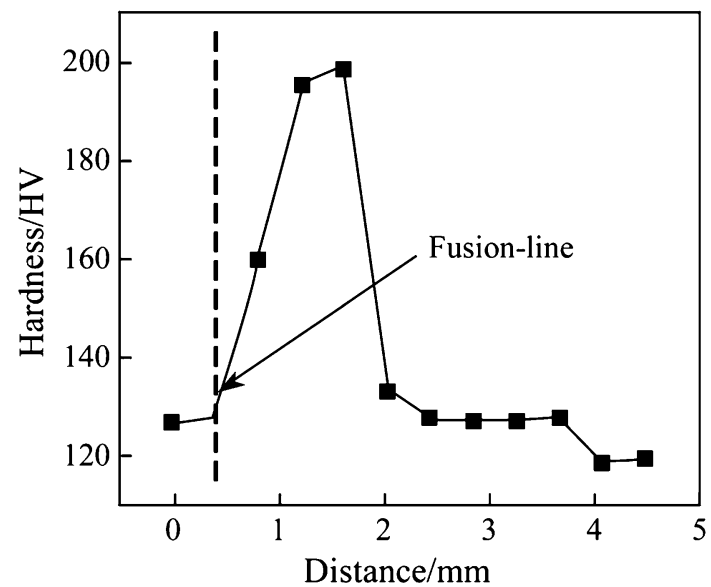

Fig. 3 Hardness from base metal to deposited layer [5]

industries. The material has a good combination of yield strength, tensile strength, creep strength, excellent process ability, weldability and good resistance to high temperature corrosion on prolonged exposure to aggressive environments. PTA rapid forming technology is especially suitable for repairing or fabricating high-value parts with high production volume. Figure 4 presented the as-deposited microstructure in a cross section vertical to the plasma arc scanning direction [7]. The staggered individual deposited
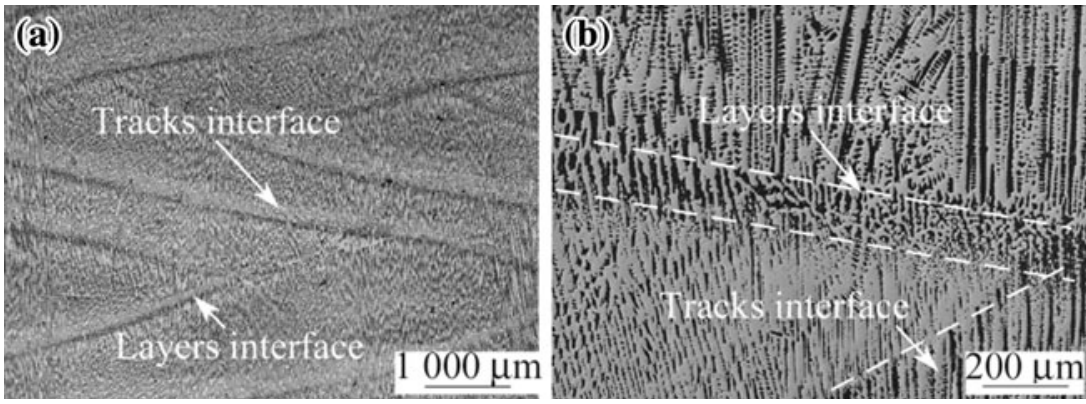

Fig. 4 Macrostructure a and high magnified microstructures $\mathbf{b}$ of the Inconel 625 thick as-deposited layer [7] 


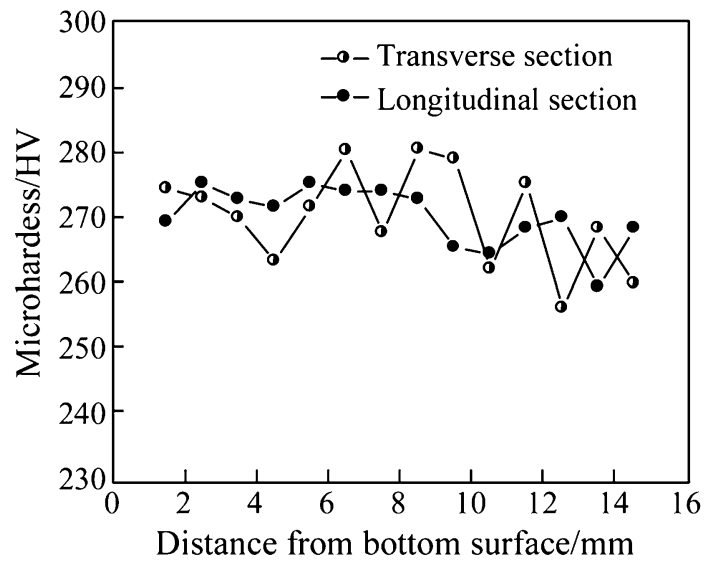

Fig. 5 Microhardness test results of thick deposited layer [7]

tracks can be observed from the low magnification microscopy, as shown in Fig. 4a. Figure 4b showed that microstructure of the sample was mostly a fine columnar dendrite structure growing epitaxially along the deposition direction. In addition, the microstructure of the overlapping interface between two adjacent deposited tracks or layers. It could be observed that a quite fine dendrite structure emerged at the interface region. The dendrites at the two sides of interface exhibited almost the same crystallographic orientation, which indicated a good consistency in crystal growth between different layers.

Microhardness measurements were carried out on the transverse and longitudinal cross-sections of the as-deposited Inconel 625 material. Figure 5 presented the micro-hardness variation profiles from bottom to upper part of the as-deposited material. The results revealed micro-hardness on the transverse cross-section in the range of $260-285 \mathrm{HV}_{0.2}$ with an obvious fluctuation. The micro-hardness of the bottom sample was higher than that of the upper sample because of the finer columnar dendrites and discrete precipitates. The
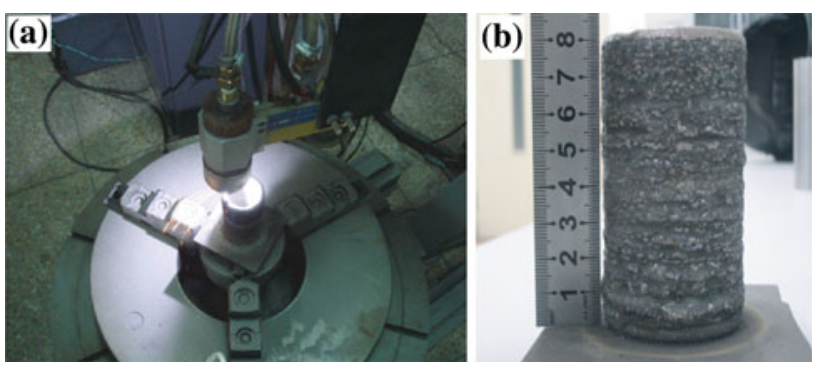

Fig. 6 Micro-plasma arc direct metal forming a process and $\mathbf{b}$ the rough part [8]

longitudinal cross-section exhibited slightly lower microhardness in the range of $260-275 \mathrm{HV}_{0.2}$ with a small fluctuation.

\subsection{Forming remanufacturing technology of Fe-based alloy new parts}

The PTA forming remanufacturing system can fulfill the rapid forming function by plasma arc powder overlaying technology, such as metal parts directly forming. In order to control the deforming of the formed parts, the PTA current must be controlled. When the PTA current was limited to $30 \mathrm{~A}$, it was called micro-plasma arc, so the dedicated parts work blank could be formed.

The cylinder part was directly formed by micro-plasma arc powder overlaying on the mild steel board with Fe313 alloy powder and the PTA current was about 27-30 A. The part was formed on base plate of mild steel Q235. The part was formed by adding materials layer by layer [8]. Figure 6 showed the micro-plasma arc direct metal forming process (see Fig. 6a) and the rough part (see Fig. 6b).

Through the altitude-direction, the metallographic specimen was made. Figure 7 illustrated the microstructure of metallographic specimen of formed part. From Fig. 7, it
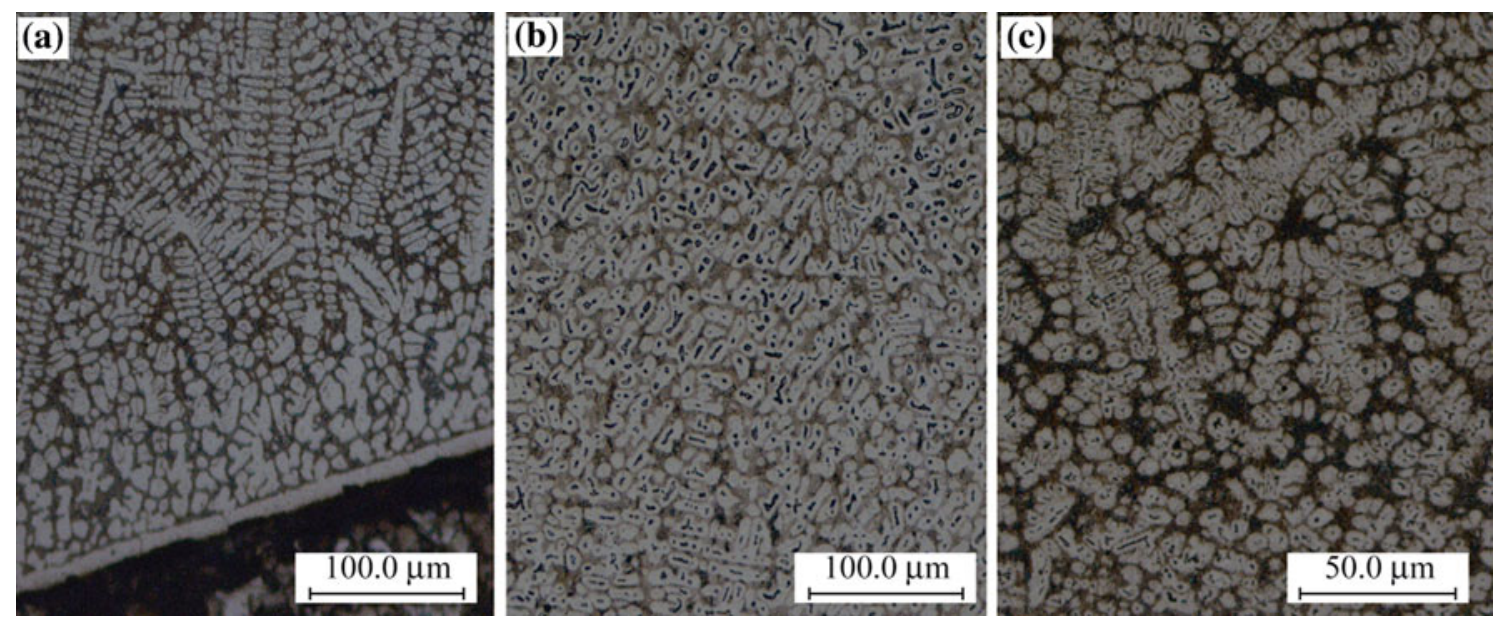

Fig. 7 Microstructure of formed part a bottom of the formed part, $\mathbf{b}$ middle of the formed part, $\mathbf{c}$ bond between deposited layers [8] 
was found that due to the heat input of the PTA arc, the temperature gradient of the part became litter, and the crystallizing direction through the temperature gradient became weak. At the same tine, the fir-tree crystal evolved to cellular crystal. Vickers hardness tester was used to test the hardness. The type of hardness distribution curve of the cylinder part was shown as U shape.

\section{Research prospect}

The PTA forming technology was multi-disciplinary cross field. This field included electric power, auto control and metallurgy technology. With the development of PTA technology in remanufacturing field, it will be applied to repair rare metal parts or the precision components those need little heat input and deforming. The high-fine PTA power supply should be studied, in order to control the heat input of PTA process accurately. The power PTA welding remanufacturing system should be improved for automatic degree by introducing computer aided manufacture (CAM) technology.

\section{References}

1. Xu BS (2007) Theory and technology of remanufacturing engineering for equipment. National Defense Industry Press, Beijing

2. Xu C (2003) Direct metal forming based on micro-plasma arc welding. Dissertation, Xi' an Jiaotong University, Xian

3. Doumanidis C (1999) Three-dimensional welding update rapid prototyping report. Am Soc Mech Eng 17(6):41-45

4. Yi J, Xu BS, Lü YH et al (2010) Application prospect of plasma welding within remanufacturing engineering. Mech Eng China 5:52-53

5. Lü YH, Xu BS, Xiang YH (2009) The microstructure and property of Ni-based overlay prepared by plasma overlaying on gray cast. China Surf Eng 2:46-48

6. Lü YH, Xu BS, Xiang YH et al (2008) Plasma transferred arc powder surfacing technology of thrust face. Key Eng Mater 373-374:43-46

7. Xu FJ, Lü YH, Xu BS et al (2012) Study on process of rapid prototyping based on pulsed plasma arc welding. Mater Sci Technol 20(3):89-93

8. Lü YH, Xu BS, Xiang YH et al (2009) Microstructure and properties of part made by micro-plasma arc direct metal formation. Heat Treat Metals 12:65-67 